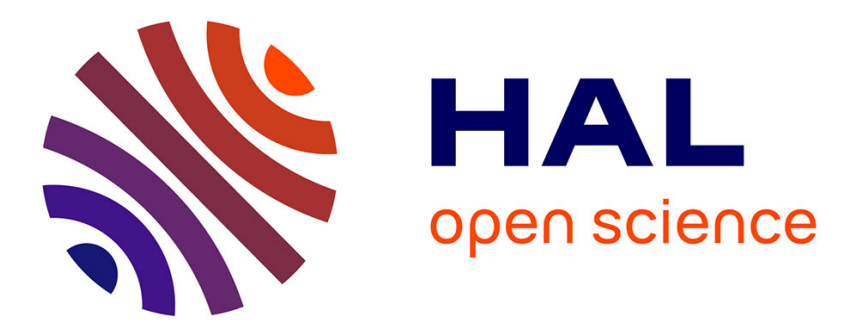

\title{
Influence of different dry milling processes on the properties of an attapulgite clay, contribution of inverse gas chromatography
}

\author{
L. Boudriche, Alain Chamayou, Rachel Calvet, B. Hamdi, H. Balard
}

\section{- To cite this version:}

L. Boudriche, Alain Chamayou, Rachel Calvet, B. Hamdi, H. Balard. Influence of different dry milling processes on the properties of an attapulgite clay, contribution of inverse gas chromatography. Powder Technology, 2014, 254, p. 352-363. 10.1016/j.powtec.2014.01.041 . hal-01611622

\author{
HAL Id: hal-01611622 \\ https://hal.science/hal-01611622
}

Submitted on 6 Nov 2019

HAL is a multi-disciplinary open access archive for the deposit and dissemination of scientific research documents, whether they are published or not. The documents may come from teaching and research institutions in France or abroad, or from public or private research centers.
L'archive ouverte pluridisciplinaire HAL, est destinée au dépôt et à la diffusion de documents scientifiques de niveau recherche, publiés ou non, émanant des établissements d'enseignement et de recherche français ou étrangers, des laboratoires publics ou privés. 


\title{
Influence of different dry milling processes on the properties of an attapulgite clay, contribution of inverse gas chromatography
}

\author{
L. Boudriche ${ }^{\mathrm{a}, \mathrm{b}, *}$, A. Chamayou ${ }^{\text {c }}$, R. Calvet ${ }^{\mathrm{c}}$, B. Hamdi ${ }^{\mathrm{b}}$, H. Balard ${ }^{\mathrm{d}}$ \\ a Centre de Recherche Scientifique et Technique en Analyse Physico-Chimique (C.R.A.P.C), BP 248, Alger Rp, 16004 Alger, Algérie \\ ${ }^{\mathrm{b}}$ Lab. d'Etude Physico-Chimique des matériaux et Application à l'Environnement, Faculté de Chimie, USTHB, BP 32 El Alia, Bab Ezzouar, 16111 Alger, Algérie \\ c Université de Toulouse, Mines Albi, CNRS, Centre RAPSODEE, Campus Jarlard, F-81013 Albi cedex 09, France \\ d Lab. Chimie Physique, (ENSCMu) ENSISA-W, 11, rue Werner, 68093 Mulhouse cedex, France
}

\begin{abstract}
A B S T R A C T
The effect of dry milling processes on the surface properties of an attapulgite clay, also called palygorskite, was investigated by carrying out experiments with different types of grinding devices. Ground products were then characterized by size measurement, scanning electron microscopy, X-ray diffraction, adsorption-desorption of $\mathrm{N}_{2}$ and inverse gas chromatography at infinite dilution (IGC-ID) as well as finite concentration conditions (IGC-FC). These analyses were performed to evaluate the changes in particle size distribution, morphology, crystallinity and surface properties of attapulgite powder, respectively. Among the tested dry grinding devices, grinding in an air jet mill (Alpine $50 \mathrm{AS}$ ) and a vibratory ball mill (Pulverisette 0 ) led to the most significant particle size reduction. SEM photomicrographs showed that a breakage of the fibrous structure took place during dry grinding. Moreover, long grinding in Pulverisette 0 resulted in the complete destruction of fibre morphology followed by agglomeration. XRD analysis showed that whatever the grinding process, the microstructure of the attapulgite was not affected. IGC confirmed that only grinding in Pulverisette 0 affected the surface properties notably. In this case, the most significant decreases were observed in the dispersive component of the surface energy (164 to $\left.116 \mathrm{~mJ} / \mathrm{m}^{2}\right)$ and in the specific surface area obtained with the octane probe $\left(114.5 \mathrm{~m}^{2} / \mathrm{g}\right.$ to $\left.62.6 \mathrm{~m}^{2} / \mathrm{g}\right)$ by IGCID and IGC-FC, respectively. At the same time, a modification of the distribution functions of the adsorption energies (DFAE), giving information about surface heterogeneity, was noticed.
\end{abstract}

Keywords:

Attapulgite

Palygorskite

Clay

Grinding

Surface properties

Inverse gas chromatography

\section{Introduction}

Grinding processes are widely used in mineral industry, particularly for the preparation of mineral fillers. The aim of these mechanical treatments is often to reduce particle size. However, depending on the ground material, grinding conditions and mechanical stresses, they often result not only in a reduction of particle size, but also in other unexpected changes that directly affect the physicochemical properties of the initial solid. Furthermore, grinding can induce an increase or decrease in the specific surface area depending on the grinding tools and parameters.

Grinding of phyllosilicate materials, like clays, was the subject of several studies, namely the grinding of montmorillonite [1,2], kaolinite [2-6], talc [6-10], chrysotile [11,12], and vermiculite [13,14]. In these papers, the influence of grinding on the morphology, microstructure, specific surface area or porous structure was investigated.

However, grinding can also modify the adsorption capacity of the phyllosilicate. Liu explored the effect of dry grinding on the capacity of attapulgite to adsorb a dye, methylene blue [15]. Liu also showed an improvement in the swelling properties of the superabsorbent

\footnotetext{
* Corresponding author. Tel.: + 213696521747.

E-mail address: boud_lil@yahoo.fr (L. Boudriche).
}

nanocomposites made of modified cellulose and ground attapulgite [16]. Suraj and Hongo studied the capacity of kaolinite [7] and vermiculite [17] respectively, to adsorb heavy metals in the course of grinding. In these studies, the authors were interested in the adsorption capacity of organic/inorganic components through end-used properties of the solid. Upstream from the end-used properties, it would be of a great interest to investigate the surface properties of the solid leading to the end-used property. There are only a few methods to measure the surface energies of powders, one of which is the inverse gas chromatography (IGC). IGC is a powerful method for the investigation of the modification of the solid surface properties upon grinding. In contrast to conventional gas chromatography, IGC studies the adsorption of a known adsorptive on an unknown adsorbent. The adsorbent (solid sample) is placed in the GC column while the adsorptive is a gas carrying probe molecules. Therefore, the probes, which are clearly identified molecules such as alkanes, acidic or basic molecules, are used to determine surface properties of the material packed into the column. In mineral field, Balard and Papirer showed the applicability of IGC to evaluate changes in the interactivity, morphology and heterogeneity of the solid surface after a grinding treatment [18-20]. In the present study, IGC was used to examine the modifications upon grinding of the surface properties of an Algerian attapulgite. This phyllosilicate material, also called palygorskite, is a rock extracted from mines or quarries. After a required 
grinding step, this material is used in powder form for a wide range of applications and fields: adsorption, catalysis, environmental, agrofood, pharmaceutical industries and production of ceramics [21,22]. In this work, we examined the influence of three types of grinding devices, a batch ball mill, a vibratory ball mill also called pulverisette zero, and an air jet mill. In the two first devices, the particles undergo impact and compression between two surfaces (the wall of the jar and a ball or between two balls). In the case of the third device, grinding occurs in an autogenous way, the impacts occur between the particles themselves. The air jet mill, widely used in the pharmaceutical industry, can produce sizes of ultra-fine particles; its advantage is that contamination with grinding media can be avoided. After the examination of the particle size, morphology and microstructure, the main objective of this work was to show that IGC is a characterisation technique suitable to emphasize the surface modifications under grinding.

\section{Theory of inverse gas chromatography (IGC)}

IGC is widely used to characterize a wide range of solid surfaces, for example attapulgite [23], aluminas [24], graphites [18], kieselguhr [25], polymers [26], pharmaceutical powders [27] and cotton [28]. This technique provides a lot of information about the analysed solid, especially concerning its surface properties (surface energy, thermodynamic properties, acid-base behaviour, etc.).

The term 'inverse' indicates that the material examined in the chromatographic column acts as the stationary phase. The probes with known properties, which are injected into the column, are chosen according to their ability to interact with the support, and thus they give information about the solid surface in the column.

Depending on the amount of injected probes, IGC can be classified as inverse gas chromatography at infinite dilution (IGC-ID) and inverse gas chromatography at finite concentration (IGC-FC).

The outcome of an IGC-ID test is the retention time of the injected probe, $t_{\mathrm{r}}$. This value reflects the intensity of interactions between the solid surface and the probe.

Retention volume, $V_{n}$, which is used to determine the thermodynamic parameters, is related to retention time by Eq. (1):

$V_{n}=D_{c}\left(t_{r}-t_{0}\right)$

where $t_{\mathrm{r}}$ is the retention time of the probes, $t_{0}$ the retention time measured with a non-adsorbing probe (methane) and $D_{c}$ is the corrected flow rate, which is related to $D_{\mathrm{m}}$, the flow rate measured with an electronic flow meter, according to Eq. (2):

$D_{\mathrm{c}}=D_{\mathrm{m}} \cdot \mathrm{j} \cdot\left(\frac{\mathrm{T}_{\mathrm{c}}}{\mathrm{T}_{\mathrm{a}}}\right)\left(\frac{\eta_{\mathrm{Ta}}}{\eta_{\mathrm{Tc}}}\right)$

where $\mathrm{T}_{\mathrm{a}}$ and $\mathrm{T}_{\mathrm{c}}$ are the ambient and oven temperatures, $\eta_{T \mathrm{~T}}$ and $\eta_{\mathrm{TC}}$ are the viscosities of the carrier gas at the $T_{a}$ and $T_{c}$ temperatures, and $j$ is the coefficient of James Martin for taking into account the compressibility of the carrier gas under the effect of the pressure drop $\Delta P$ as shown in Eq. (3):

$\mathrm{j}=\frac{3}{2} \frac{\left(1+\frac{\Delta P}{P_{a t m}}\right)^{2}-1}{\left(1+\frac{\Delta P}{P_{a t m}}\right)^{3}-1}$

\subsection{Inverse gas chromatography at infinite dilution (IGC-ID)}

\subsubsection{The dispersive component of the surface energy, $\gamma_{s}^{d}$}

This parameter traduces the potential of a solid to undergo London or dispersive interactions. It is calculated according to the Dorris and Gray approach [29], by injecting linear alkanes (pentane, hexane, heptane, etc.). The slope of the straight line obtained when plotting
$\operatorname{RTLn}\left(\mathrm{V}_{\mathrm{n}}\right)$ versus the number of carbon atoms of the alkane probes, $\Delta$ $G_{a}^{c+2}$, gives access to $\gamma_{s}^{d}$ by applying Eq. (4):

$\gamma_{s}^{d}=\frac{\left(\Delta G_{a}^{C H_{2}}\right)^{2}}{4 N^{2} a_{C_{2}}^{2} \gamma_{C H_{2}}}=\frac{\left(R T L n \frac{V_{n}(n+1)}{V_{n}(n)}\right)^{2}}{4 N^{2} a_{C H_{2}}^{2} \gamma_{C H_{2}}}$

where $N$ is Avogadro's number, $a_{\mathrm{CH}_{2}}$ is the surface area of one adsorbed methylene group $\left(0.06 \mathrm{~nm}^{2}\right), \gamma_{\mathrm{CH}_{2}}$ is the surface energy of a solid with only methylene groups, i.e., polyethylene $\left(\gamma_{\mathrm{CH}_{2}}=35.6+0.058(293-T)\right)$ in $\mathrm{mJ} / \mathrm{m}^{2}$, with $T$ being the oven temperature

\subsubsection{The nanomorphology index, $I_{M}\left(\chi_{t}\right)$}

The solid surface is never entirely smooth at the molecular scale due to the existence of structural defects, which are emphasized by the size exclusion effects of some probes during the chromatographic process. Indeed, branched or cyclic alkanes can behave differently from linear alkanes when adsorbed on the surface of a rough solid. This effect of surface morphology can be quantified by comparing the adsorption behaviour of linear and non-linear (branched or cyclic) alkanes, using the nanomorphology index, $I_{M}\left(\chi_{t}\right)$ [30], defined in Eq. (5):

$I_{M}\left(\chi_{t}\right)=e^{\frac{-\Delta G_{a}^{M}}{R I}}$

where $\Delta G_{a}^{M}$ is the variation between the representative point of the branched or cyclic alkane and the reference n-alkane straight line, $\chi_{t}$ is the topology index proposed by Brendle [31] and derived from Wiener's topology indices.

When $I_{M}\left(\chi_{t}\right)$ is equal to 1 , the solid surface can be considered as flat at the molecular scale. Under these conditions, the bulky (branched or cyclic) and the linear alkanes have access to the same surface. So both probes have similar retention times and variations of free energy of adsorption (RT $\ln V n$ ). $\Delta G_{a}^{M}$ is near zero.

When the surface roughness increases, $I_{M}\left(\chi_{t}\right)$ decreases and its value can reach 0.1 as in the case of talc [32]. The access to the rough parts of the surface is more limited for cyclic (or branched) alkane molecules than for linear ones due to steric hindrance. In the case of the cyclic (or branched) alkanes, the retention time and the variation of the free energy are weaker, and $\Delta G_{a}^{M}$ deviates from 0 .

\subsubsection{The specific component of the surface energy, $I_{s p}$}

This parameter characterizes the polar surface and acid-base interactions; it represents the contribution of specific interactions, $\Delta G_{a}^{s p}$, also denoted by $I_{\mathrm{sp}}$, between polar probes and the solid surface [31]. It can be determined from the variation between the global free energy of the injected polar probe, $\Delta G_{a}$, and the straight line of alkane probes $\Delta G_{a}^{d}$ (Fig. 1).

The principles, advantages and limitations of IGC-ID have been summarized in a review paper [31] and will not, therefore, be discussed here.

\subsection{Inverse gas chromatography at finite concentration (IGC-FC)}

In the case of IGC-FC, a few microlitres of the liquid probe are injected into a column containing the solid to be analysed, in order to provide an approximately mono-layered coverage on the surface of the solid. The results of this technique reflect the interaction of probe molecules with all the sites on the solid surface. The obtained chromatographic peak (Fig. 2) is highly asymmetric when ideal, nonlinear conditions are fulfilled. Due to the presence of very-high-energy adsorption sites, it is usually observed that a non-negligible part of the injected probe is not eluted despite of the fact that the signal returns to the initial baseline. 


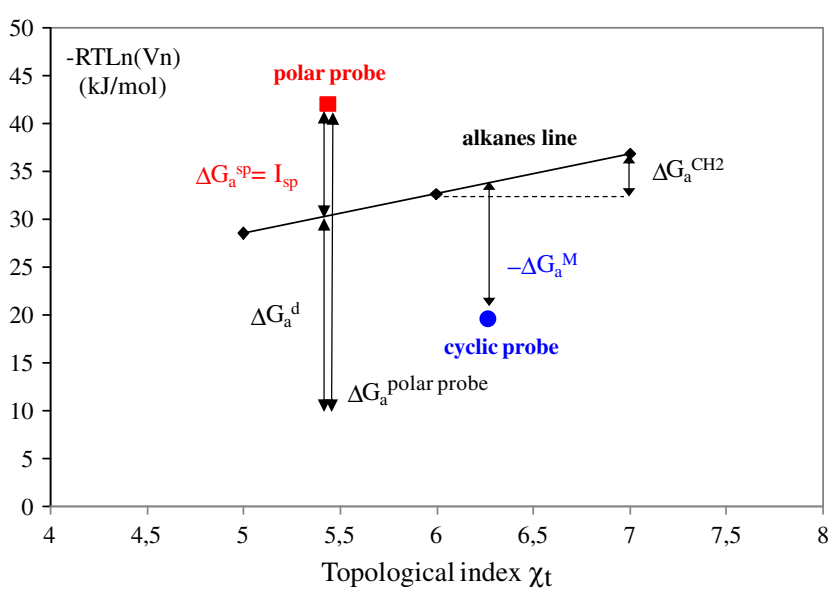

Fig. 1. Experimental measurements of the free energy of adsorption for different probes.

\subsubsection{Irreversibility index}

In order to assess the irreversibly adsorbed amount, the temperature of the chromatograph oven is increased to a conditioning temperature, leading to the appearance of a small secondary peak. The ratio of the area under this thermodesorption peak $\left(S_{\text {th }}\right)$ and the total area of the chromatogram $\left(S_{\mathrm{rv}}\right)$ gives an assessment to the irreversibility index $\left(\mathrm{I}_{\mathrm{irr}}\right)$, representing the amount of irreversible adsorbed probe material. This index represents the amount of high energy sites. For example with the isopropanol probe, $\mathrm{I}_{\text {irr }}$ gives a measurement of the sites able to interact with hydrogen bond. The irreversibility index $\left(\mathrm{I}_{\text {irr }}\right)$, as previously defined [18], can be calculated according to Eq. (6):

$\mathrm{I}_{\mathrm{irr}}=\mathrm{S}_{\mathrm{th}} /\left(\mathrm{S}_{\mathrm{rv}}+\mathrm{S}_{\mathrm{th}}\right)$.

\subsubsection{Isotherm of desorption}

By applying the 'elution characteristic point method' (ECP) to the reversible isothermal part of the experimental chromatogram, IGC-FC also gives access to the desorption isotherm of the probe molecule, from a single chromatographic peak [33]. The first derivative of the isotherm is directly related to the net retention time of each point in the diffuse front of the chromatogram as shown by Eq. (7):

$$
\left(\frac{\partial N}{\partial P}\right)_{L, t_{r}}=\frac{D_{c}}{m R T}\left(t_{r}-t_{0}\right)
$$

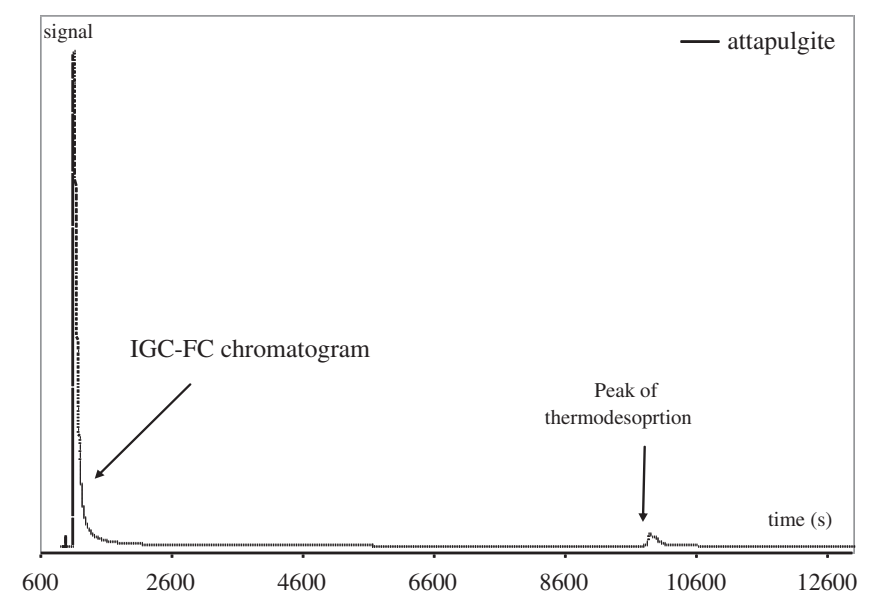

Fig. 2. Experimental chromatogram and the associated thermodesorption peak of attapulgite obtained with octane probe at $70{ }^{\circ} \mathrm{C}$ where, for each point on the rear diffuse profile of the chromatogram, $N$ is the number of adsorbed probe molecules, $P$ is the partial pressure of the probe compound at the output of the column, $L$ is the column length, $t_{\mathrm{r}}$ is the retention time of this point, $t_{0}$ is the retention time of $\mathrm{CH}_{4}, D_{\mathrm{c}}$ is the corrected flow rate, $m$ is the mass of the column packing and $T$ is the oven temperature.

By integrating Eq. (7), the desorption isotherm of the probe can be obtained, the pressure of the probe being directly related to the height of the signal at this point. Applying the BET linearization to this isotherm, its main parameters, the specific surface area, the Henry and the BET constants can be assessed. All calculations were performed using a special software from the ADSCIENTIS society (Wittelsheim, France).

On the other hand, the shape analysis of the isotherm reveals the distribution functions of the adsorption energy sites (DF), which are related to the surface heterogeneity of the column packing. The calculation of DF is based on a physical adsorption model, which assumes that the global isotherm can be considered to be the sum of local isotherms of adsorption on isoenergetic domains (patchwork model) $[18,19,34]$. Thus, the distribution function of the relative abundance of each type of domain, having the same characteristic energy of interaction $(\varepsilon)$, is given by the following integral (Eq. (8)):

$N(T, P)=N_{0} \int_{\Omega} \theta(\varepsilon, T, P) \chi(\varepsilon) d \varepsilon$

where $N(T, P)$ is the number of molecules adsorbed at pressure $P$ and temperature $T, N_{0}$ is the number of molecules which can form a monolayer, $\theta(\varepsilon, T, P)$ is the local isotherm corresponding to adsorption sites having the same characteristic adsorption energy $\varepsilon, \chi(\varepsilon)$ is the socalled distribution function of the adsorption energies (DFAE) describing the energies which exist at the gas-solid interface, $\Omega$ is the physical domain of the adsorption energy, and $\varepsilon$ is the characteristic energy.

\subsubsection{Heterogeneity index}

The index of surface heterogeneity, $I_{\text {hete, }}$ defined in Eq. (9), which permits the comparison of the surface heterogeneity of the studied samples, can be determined by comparing the computed DF with the DF describing a homogeneous surface that fits the left descending branch of the experimental DF towards the lowest interaction energies [18]:

$I_{\text {hete }}=\frac{A-A_{\mathrm{H}}}{A}$

where $A$ is the area under the experimental DF and $A_{\mathrm{H}}$ is that under the homogeneous DF.

The distribution functions were computed using a special software from the ADSCIENTIS society (Wittelsheim, France).

\section{Materials and methods}

\subsection{The attapulgite clay}

The attapulgite used in this study was extracted from the Ghoufi's region, located at the North East of Algeria. This material is a fibrous $\mathrm{Mg}$ clay [35], generally containing large amounts of $\mathrm{Al}(\mathrm{III})$ and $\mathrm{Fe}(\mathrm{III})$ cations [36,37].

This clay belongs to the class of 2:1 phyllosilicates [38], in which the sheets of the silica tetrahedrons are periodically inverted with respect to the tetrahedral bases. Consequently, the octahedral sheets are periodically interrupted and terminal cations must complete their coordination sphere with water molecules. This configuration confers fibrous structure to attapulgite.

Attapulgite has carbonates, such as dolomite and calcite, in its structure. By removing these carbonates, a treatment with an acid allows the formation of porous structure in the mineral and to create a higher 
Table 1

Parameters and operating conditions for each grinding device.

\begin{tabular}{|c|c|c|c|}
\hline & Ball mill & Air jet mill & Vibration mill \\
\hline Company & Faure equipment & Hosokawa Micron & Fritsch \\
\hline Device & Marne 1 & Alpine $50 \mathrm{AS}$ & Pulverisette 0 \\
\hline \multirow[t]{5}{*}{ Equipment configuration } & - Volume of jars (L): 1 & Flow rate $(\mathrm{g} / \mathrm{min}): 0.64$ & A vibrating agathe vessel \\
\hline & - Amount of ceramic grinding medium $(\mathrm{kg}): 1$ & Pressures (bar): & Ball diameter $(\mathrm{cm}): 5$ \\
\hline & Diameters (mm (\%)) & - Injection: 4 & Amplitude of vibration (mm): 2 \\
\hline & $24(20), 19(20), 12(60)$ & - Grinding: 3.5 & \\
\hline & $-60 \%$ of critical speed & & \\
\hline Amount of attapulgite (additives) & $-200 \mathrm{~mL}$ or $170 \mathrm{~g}$ & & $-12 \mathrm{~mL}$ or $10 \mathrm{~g}$ \\
\hline
\end{tabular}

surface area. In our study, this acid treatment was carried out in a reflux system at the boiling point of the $1 \mathrm{M} \mathrm{HCl}$ solution, for $6 \mathrm{~h}$. The obtained solution was filtered and the residue was washed with distilled water several times to ensure that the chloride ions were totally removed from the residue. The sample was then dried at $110{ }^{\circ} \mathrm{C}$ overnight before milling.

\subsection{Dry grinding conditions}

Three different types of grinding mills (batch ball milling, air jet micronizer and vibratory ball mill) which were operated in a dry way, were used to investigate the influence of grinding processes on the properties of attapulgite.

Batch ball milling experiments were carried out using a MARNE 1 device supplied by the FAURE Equipment Company. Jars of $1 \mathrm{~L}$ were filled with $1 \mathrm{~kg}$ of ceramic grinding medium (balls with different diameters: $20 \%$ of $24 \mathrm{~mm}, 20 \%$ of $19 \mathrm{~mm}$ and $60 \%$ of $12 \mathrm{~mm}$ ) and $170 \mathrm{~g}$ (i.e. $200 \mathrm{~cm}^{3}$ ) of attapulgite powder. The jars rotating speed was fixed at $70 \mathrm{rpm}$ i.e. $60 \%$ of the critical speed as recommended by the device provider. Two additional experiments were carried out with additives, one with $1 \mathrm{wt} . \%$ of ethanol and the other one with $1 \mathrm{wt} . \%$ of adipic acid. These additives were used in milling experiments in order to prevent agglomeration of fine particles.

The micronization experiments were carried out using a 50 AS pancake air jet mill supplied by the HOSOKAWA MICRON Company with 4.0 and 3.5 bar injection and grinding pressures, respectively.

A lab-scale vibratory ball mill called "Pulverisette 0 ", provided by the Fritsch Company, was used to perform milling experiments. This device consists in an agate vibrating vessel equipped with a $5 \mathrm{~cm}$ ball. The vibration is mechanically transferred from the vessel to the ball that serves as grinding tool by multi-impacts on the powder bed (impact, friction and compression breakage mechanisms). In our experiments, the vibration amplitude of the vessel was fixed at $2 \mathrm{~mm}$ and $10 \mathrm{~g}$ samples were ground by varying the grinding time from $30 \mathrm{~min}$ to $60 \mathrm{~h}$.

The main parameters and operating conditions for each type of mill are summarized in Table 1.

Table 2

Operating conditions for Inverse Gas Chromatography at Infinite Dilution (IGC-ID) and Finite Concentration (IGC-FC).

\begin{tabular}{|c|c|c|}
\hline & IGC-ID & IGC-FC \\
\hline Device & \multicolumn{2}{|c|}{ Agilent $7890 \mathrm{~A}$ and 6890} \\
\hline Carrier gas flow & \multicolumn{2}{|c|}{ Helium $30 \mathrm{~mL} / \mathrm{min}$} \\
\hline Conditioning temperature/duration & \multicolumn{2}{|c|}{$150{ }^{\circ} \mathrm{C} /$ oven night } \\
\hline Temperatures: injector/detector & \multicolumn{2}{|c|}{$130^{\circ} \mathrm{C} / 200^{\circ} \mathrm{C}$} \\
\hline Oven & $130{ }^{\circ} \mathrm{C}$ & $\begin{array}{l}43^{\circ} \mathrm{C} \text { (octane) } \\
53^{\circ} \mathrm{C} \text { (isopropanol) }\end{array}$ \\
\hline $\begin{array}{l}\text { Column characteristics } \\
\text { length/internal } \\
\text { diameter }\end{array}$ & $20 \mathrm{~mm} / 6.35 \mathrm{~mm}$ & $\begin{array}{l}10 \mathrm{~mm} / 6.35 \text { or } \\
3.18 \mathrm{~mm}\end{array}$ \\
\hline Probes & $\begin{array}{l}\text { Hexane, heptane, } \\
\text { octane cyclooctane, } \\
\text { dichloromethane, } \\
\text { chloroform }\end{array}$ & Octane, isopropanol \\
\hline
\end{tabular}

\subsection{Characterization methods}

Particle size distribution measurements were performed using a laser diffraction method on a Malvern Mastersizer 2000 device. The samples were analysed using a dry-way feeder (Scirocco, Malvern) with a dispersion pressure of 3.5 bars. Different diameter characteristics for particle size distribution were obtained such as the $d_{10}, d_{50}, d_{90}$ as well as the mean volume diameter $\mathrm{d}_{4 / 3}$, the Sauter or mean surface/volume diameter $d_{3 / 2}$, and the Span value as described in Eq. (10), characterizing the spreading of the distribution:

Span $=\frac{d_{90}-d_{10}}{d_{50}}$.

Particle morphology was investigated using a scanning electron microscope (Philips XL 30 model ESEM-FEG) operating at $3 \mathrm{kV}$.

Phase identification was performed on a Panalytical X'PERT Pro diffractometer (Philips) (CuK $\alpha$ radiation) with a step size of $0.017^{\circ}$ for $2 \theta$ angles ranging from $5^{\circ}$ to $80^{\circ}$. The $2 \theta$ values were analysed with the X'Pert High Score software and compared with the ICDD (International Centre for Diffraction Data) database.

The BET specific surface areas, BET constants, meso- and micropore volumes were determined using nitrogen adsorption at $77 \mathrm{~K}$ (ASAP 2010, Micromeritics) by applying the BET, BJH, and $t$-plot methods. The samples were out gassed before analysis, at $105^{\circ} \mathrm{C}$ for $24 \mathrm{~h}$ at a pressure of $8 \cdot 10^{-3} \mathrm{mbar}$.

The IGC measurements were performed with two GC devices (Agilent $7890 \mathrm{~A}$ and 6890), fitted with sensitive flame ionization detectors (FID). Helium was used as carrier gas with a flow rate of $30 \mathrm{~mL} / \mathrm{min}$ measured with an electronic flowmeter (Flow500-Agilent). The injector and detector temperatures were $130{ }^{\circ} \mathrm{C}$ and $200{ }^{\circ} \mathrm{C}$, respectively. The

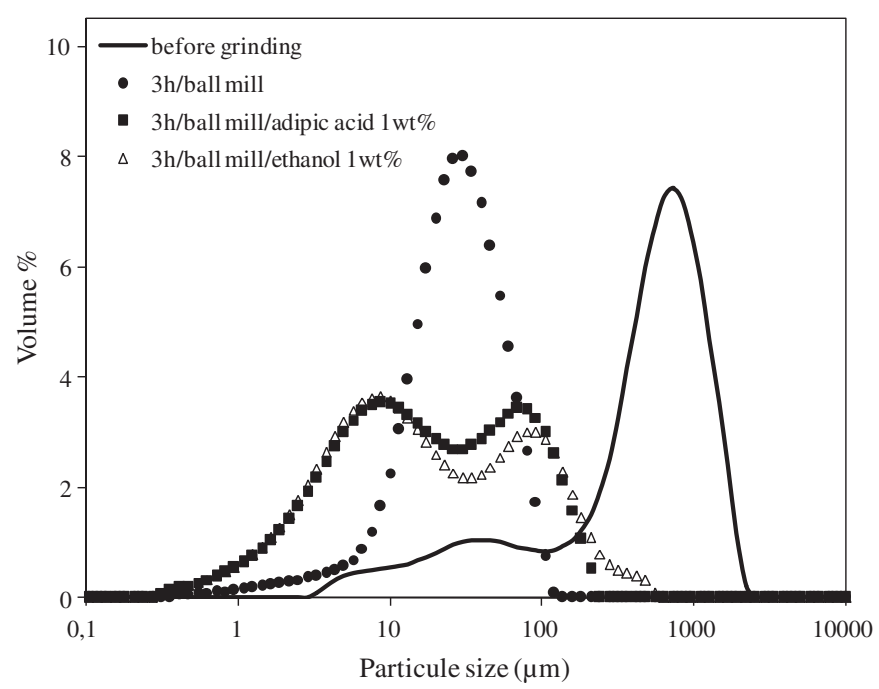

Fig. 3. Particle size distribution of attapulgite ground in the ball mill, with and without additives. 


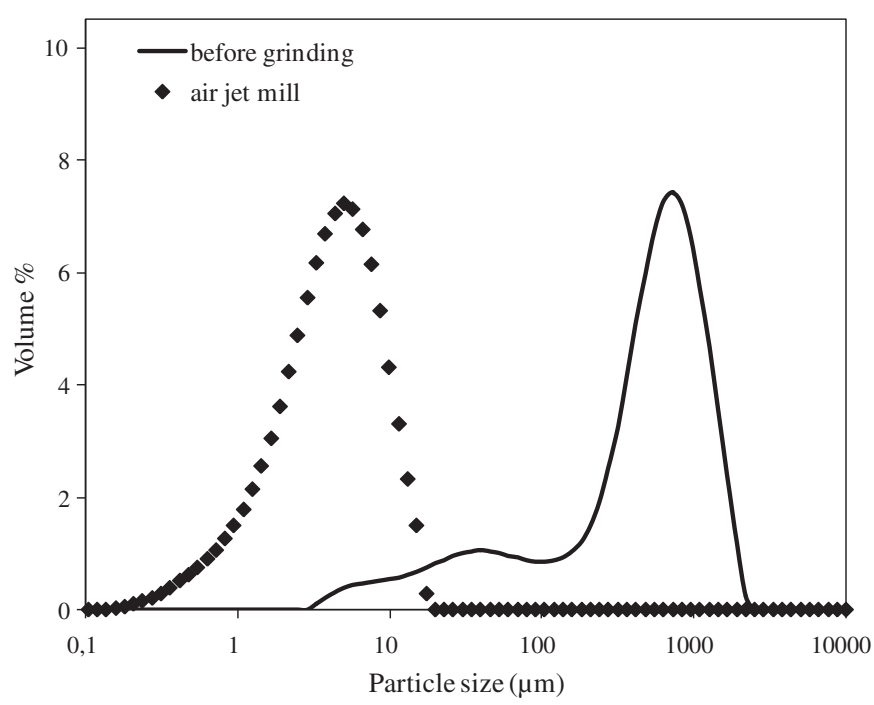

Fig. 4. Particle size distribution of attapulgite ground in the air jet mill.

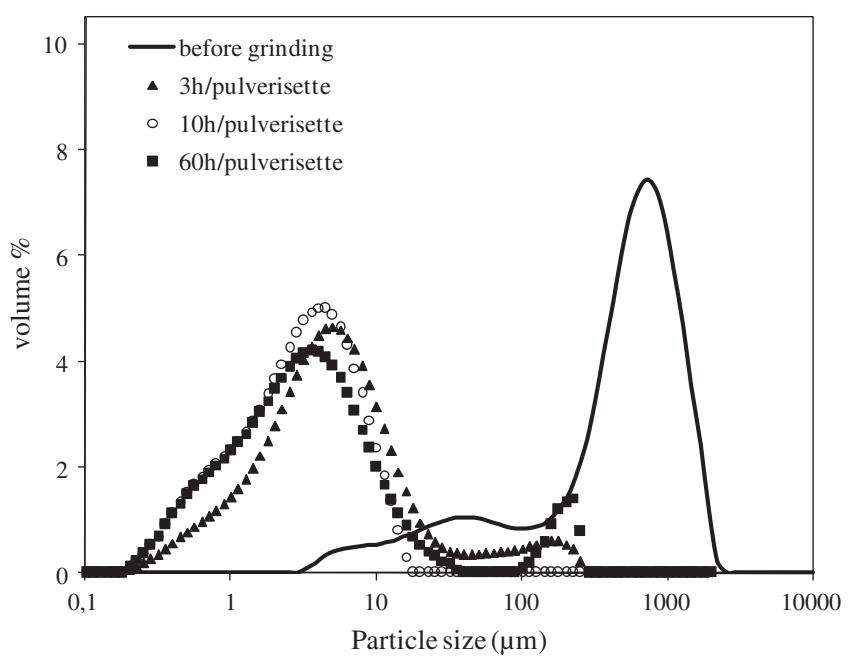

Fig. 5. Particle size distribution of attapulgite ground in Pulverisette 0, at different times.

columns were filled with a mixture of attapulgite powder and glass beads. The amount of powder in the column was chosen according to the pressure drop, which had to be lower than 1 bar in order to avoid leaks at the septum and fittings.

The IGC-ID study was performed at an oven temperature of $130{ }^{\circ} \mathrm{C}$, using stainless steel columns of $20 \mathrm{~cm}$ length and $6.35 \mathrm{~mm}$ internal diameter. The columns were conditioned overnight at $150{ }^{\circ} \mathrm{C}$, and the analyses were carried out at $130{ }^{\circ} \mathrm{C}$. It is to note that the surface properties of attapulgite powder do not change at $150{ }^{\circ} \mathrm{C}$. (a)

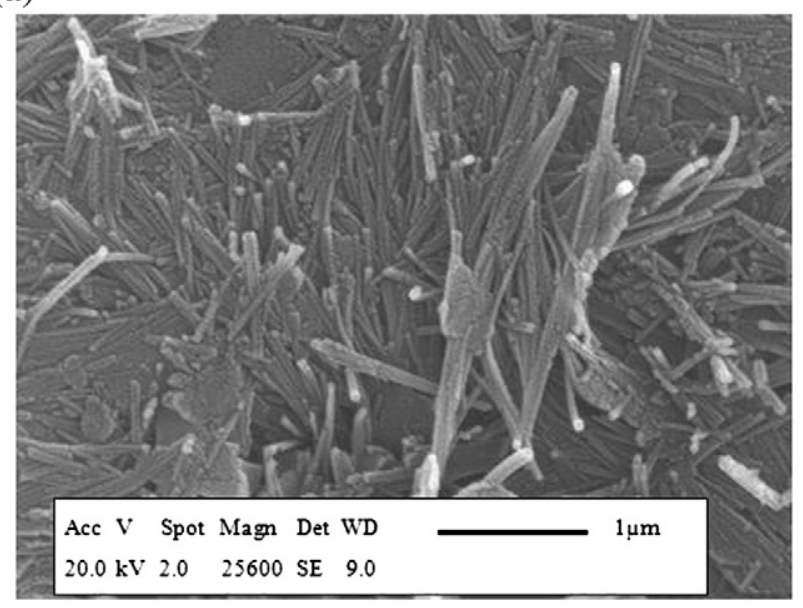

(b)

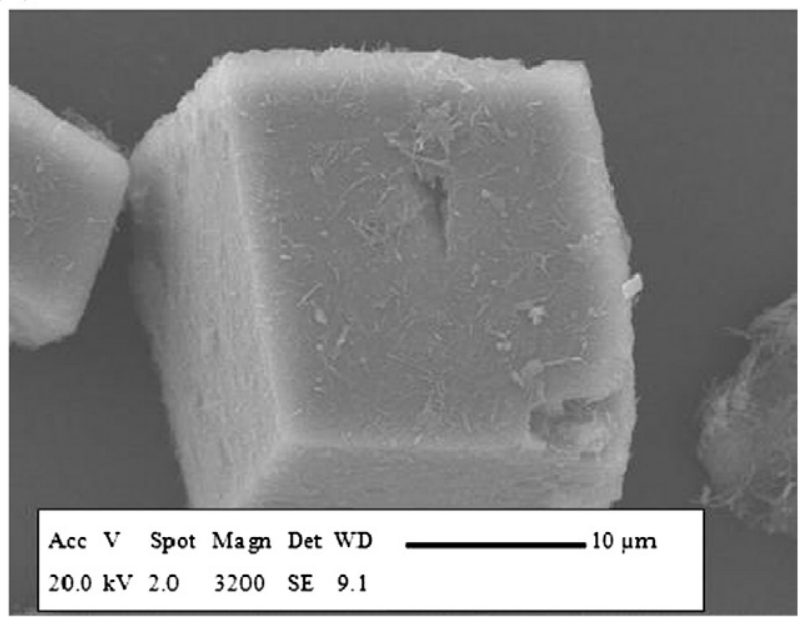

Fig. 6. Micrographies of raw attapulgite, (a) fibres and (b) carbonates.

The probes used were linear alkanes (hexane $\mathrm{C6}$, heptane $\mathrm{C} 7$ and octane $\mathrm{C} 8$ ), a cyclic alkane, cyclooctane ( $\mathrm{Cycl} 8)$ and polar probes (chloroform, $\mathrm{CHCl}_{3}$, and dichloromethane, $\mathrm{CH}_{2} \mathrm{Cl}_{2}$ ). These probes were of chromatographic grade (>99\%) purity.

For IGC-FC, the chromatographic columns were $10 \mathrm{~cm}$ in length and $6.35 \mathrm{~mm}$ or $3.18 \mathrm{~mm}$ in internal diameter. The conditioning temperature was $150{ }^{\circ} \mathrm{C}$. Analysis temperature depended on the probe used, according to the Conder criterion [23]. This criterion states that the contribution of probe vapour to the flow of carrier gas should not exceed $5 \%$ of the initial flow at the maximum of the chromatographic peak. Two probes were examined by IGC-FC, octane (C8) at $53{ }^{\circ} \mathrm{C}$ and isopropanol (IP) at $43^{\circ} \mathrm{C}$. We chose a nonpolar probe, octane, to study surface morphology and a polar probe, isopropanol, to examine the surface chemistry of ground samples. The various operating conditions for IGC analysis are summarized in Table 2.

Table 3

Means characteristic diameters of the attapulgite particles before and after dry-grinding.

\begin{tabular}{|c|c|c|c|c|c|c|c|}
\hline & & $\mathrm{d}_{10}(\mu \mathrm{m})$ & $\mathrm{d}_{50}(\mu \mathrm{m})$ & $\mathrm{d}_{90}(\mu \mathrm{m})$ & Span & $\mathrm{d}_{4 / 3}(\mu \mathrm{m})$ & $\mathrm{d}_{3 / 2}(\mu \mathrm{m})$ \\
\hline \multicolumn{2}{|c|}{ Attapulgite before processing } & 31.0 & 510 & 1159 & 2.21 & 563.2 & 76.8 \\
\hline \multirow{3}{*}{ Ball mill } & $3 \mathrm{~h}$ & 9.22 & 25.5 & 58.1 & 1.96 & 30.0 & 13.7 \\
\hline & $3 \mathrm{~h}$ (1 wt.\% ethanol) & 2.74 & 16.3 & 136 & 8.22 & 40.5 & 6.75 \\
\hline & 3 h (1 wt.\% adipic acid) & 2.87 & 18.1 & 112 & 6.01 & 50.0 & 6.49 \\
\hline Air jet mill & - & 1.32 & 4.68 & 10.8 & 2.03 & 5.5 & 2.66 \\
\hline \multirow[t]{3}{*}{ Pulverisette 0} & $3 \mathrm{~h}$ & 1.08 & 4.87 & 23.0 & 4.49 & 15.7 & 2.55 \\
\hline & $10 \mathrm{~h}$ & 0.68 & 3.06 & 8.29 & 2.48 & 3.86 & 1.66 \\
\hline & $60 \mathrm{~h}$ & 0.70 & 3.36 & 16.3 & 4.63 & 18.0 & 1.77 \\
\hline
\end{tabular}




\section{Results and discussion}

\subsection{Particle size analysis}

The performances of grinding processes were first evaluated by their ability to reduce size reduction (Figs. 3, 4,5). The results concerning the main characteristic diameters are reported in Table 3.

The raw attapulgite is the passing fraction using a $1 \mathrm{~mm}$ sieve after "Hammer crushing" and sieving of blocks extracted from the deposit. This fraction, noted in the study as "before grinding" was taken as reference. The particle size distribution of the raw attapulgite obtained by the measurements with the Malvern Mastersizer device, fell in the range of 3 to $2000 \mu \mathrm{m}$ with a main population (in volume \%) centred at about $1000 \mu \mathrm{m}$ and a second one below $100 \mu \mathrm{m}$. The significant difference between the $d_{4 / 3}$ and $d_{3 / 2}$ diameters (Table 3 ), is a consequence of the spread of the particle size distribution (presence of fine particles) which can be observed in Fig. 3.

Under the influence of grinding, independently of the process, particle size decreased considerably. However, the air jet mill and the vibratory ball mill were clearly more efficient than the dry ball mill. This was especially true for the jet mill if we consider the residence time required to obtain the size reduction.

A previous study [39] conducted in the ball mill investigated the influence of milling time on particle size distribution. After $2 \mathrm{~h}$, the grinding process reached its limits in terms of particle size reduction. The main characteristic diameters values obtained after $3 \mathrm{~h}$ were similar to those after $2 \mathrm{~h}$. All the experiments in the ball mill, with or without additives, were performed for $3 \mathrm{~h}$. (a)

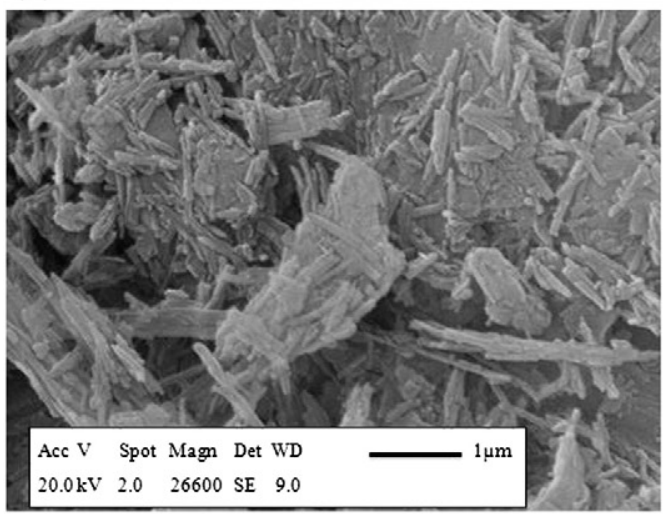

(c)

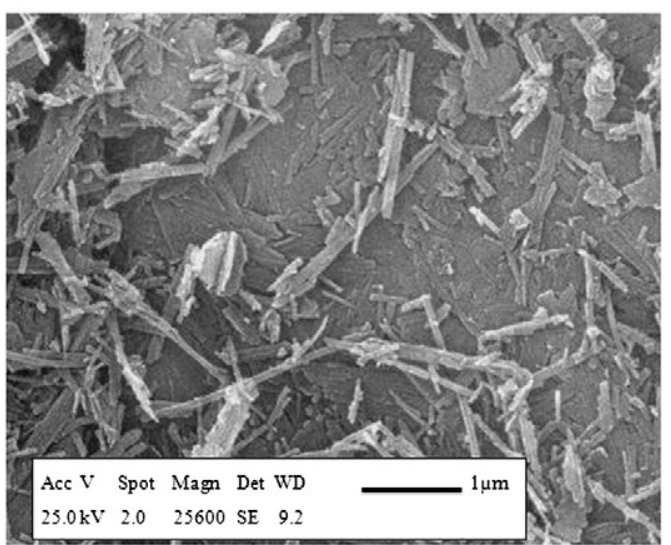

(e)

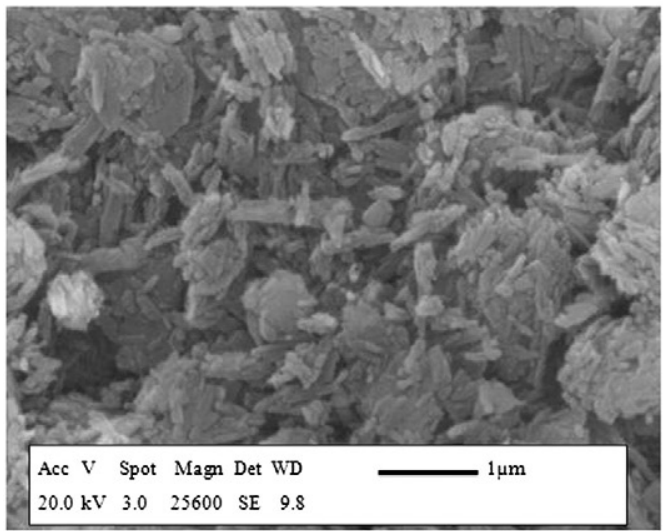

(b)

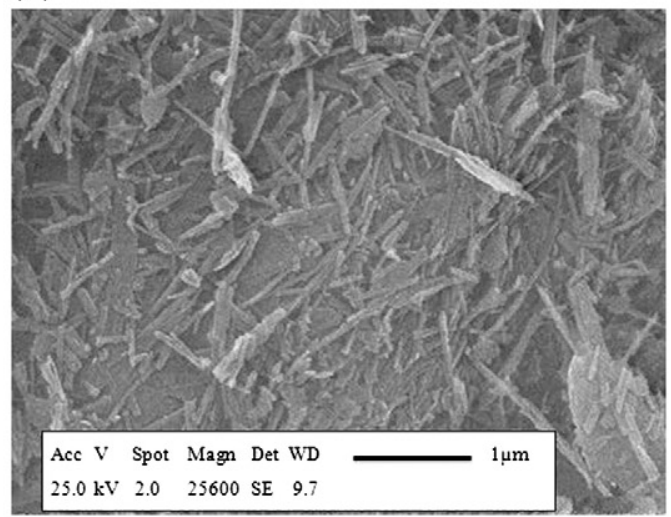

(d)

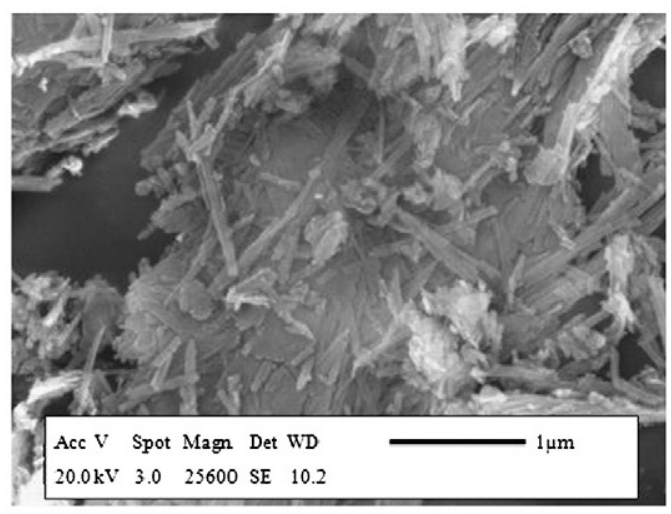

(f)

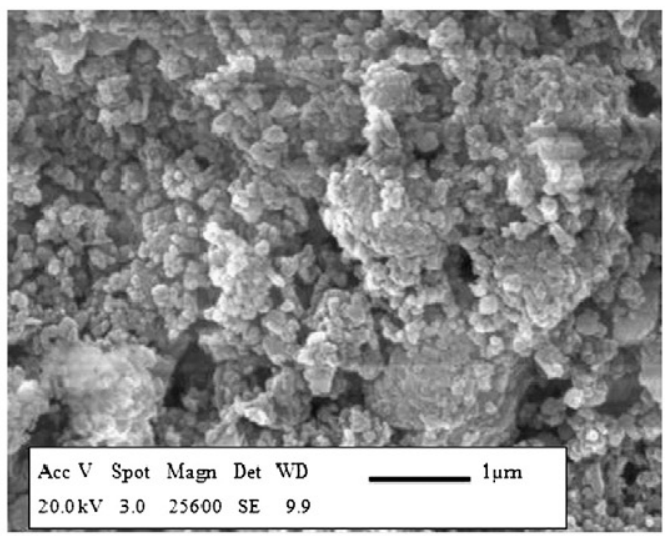

Fig. 7. Attapulgite, ground $3 \mathrm{~h}$ in ball mill without additives (a), ground $3 \mathrm{~h}$ in ball mill with adipic acid $1 \%$ (b), ground $3 \mathrm{~h}$ in ball mill with ethanol $1 \%$ (c), ground in air jet mill (d), ground 3 $\mathrm{h}$ in Pulverisette 0 (e) and ground $60 \mathrm{~h}$ in Pulverisette 0 (f). 
Fig. 3. shows the size distribution after $3 \mathrm{~h}$ of grinding in the ball mill. The initial main peak centred around $1000 \mu \mathrm{m}$ moved after $3 \mathrm{~h}$ of grinding to a value between 10 and $100 \mu \mathrm{m}$.

Grinding experiments were carried out in the same ball mill in the presence of additives ( $1 \mathrm{wt} . \%$ of ethanol or adipic acid), the role of which was to avoid re-agglomeration of fine particles and/or to promote the propagation of fronts fracture (Rehbinder effect) [40]. The size distributions show that the additives, even in very limited quantities ( $1 \mathrm{wt} . \%$ of ethanol or adipic acid) allow to reach a range of finer particles. A bimodal distribution is observed, with a population of very fine particles showing diameters smaller than $10 \mu \mathrm{m}$. The population centred at $90 \mu \mathrm{m}$ can result in the agglomeration of the smaller particles. So it would be interesting to use a higher percentage of additives to limit re-agglomeration. Higher span values (Table 3 ) indicate the spreading of the size distribution in the presence of the additives, compared to the lower span value obtained without additives that indicated a narrower distribution. The comparison of size distribution curves obtained after grinding with and without additives is a clear evidence that there are different grinding mechanisms. At this level of the study, it is not possible to give more details on the breakage mechanism.

The air-jet mill led to a monomodal size distribution (Fig. 4) with a population of very fine particles having diameters smaller than $10 \mu \mathrm{m}$ and a small difference between the values of $\mathrm{d}_{4 / 3}$ and $\mathrm{d}_{3 / 2}$ as shown in Table 3. In this device, due to injection and grinding pressures, the impact and compression forces are higher than those involved in the ball mill, explaining the better efficiency of grinding.

After a long grinding time $(60 \mathrm{~h})$ in Pulverisette 0 , the particles become finer than in the air jet mill. Due to the vibration amplitude and the agate ball, the impact and compression forces were higher in Pulverisette 0 than those involved in the air-jet mill. However a wider size distribution was observed in Pulverisette 0 (Fig. 5). The values of characteristic diameters reached a limit after $10 \mathrm{~h}$ of grinding (Table 3 ). In addition, a re-agglomeration phenomenon of very fine particles occurred and this resulted in a new peak due to a few particles larger than $100 \mu \mathrm{m}$. The observed values of $\mathrm{d}_{4 / 3}$ and $\mathrm{d}_{3 / 2}$ reflected the significant presence of fine particles along with others of large diameter.

After the study of the particle size distribution, scanning electron microscopy was performed to evaluate the influence of grinding on the morphology of the particles.

\subsection{Analysis of morphology and microstructure by scanning electron mi- croscopy (SEM)}

The morphological properties of raw and ground samples prepared with various grinding mills in a dry way were observed by SEM analysis.

The raw attapulgite is fibrous (Fig. 6a), with fibres having an average length smaller than $3 \mu \mathrm{m}$. The cubic inclusions in the structure (Fig. $6 \mathrm{~b}$ ) are related to carbonate impurities.

The photomicrographs (Fig. 7) show that, whatever the grinding process, the fibres became shorter and more disorganized compared to the raw material (Fig. 6a). In Pulverisette 0, fibre morphology was totally destructed after $60 \mathrm{~h}$ milling (Fig. 7f). This structure agrees with the re-agglomeration, which was already observed during particle size analysis (Fig. 5).

A study of dry grinding was carried out by Vucelic [41] on an other fibrous clay, a sepiolite from Serbia, with a milling time over $24 \mathrm{~h}$ in a ball mill. It was shown that, after grinding, the particles had the appearance of irregular spheres with a diameter smaller than $20 \mu \mathrm{m}$. According to the author, the spherical shape was the result of the collisions of particles with the balls, but also with other particles. The SEM photomicrographs revealed that these particles were spherical agglomerates composed of numerous needle shaped particles randomly oriented. The grinding of the same sepiolite in an air jet mill preserved fibrous morphology with the separation of bundles in isolated fibres. Another study of a Spanish sepiolite [42] revealed the stability of sepiolite upon grinding, whatever its origin, for milling times shorter than $24 \mathrm{~h}$.

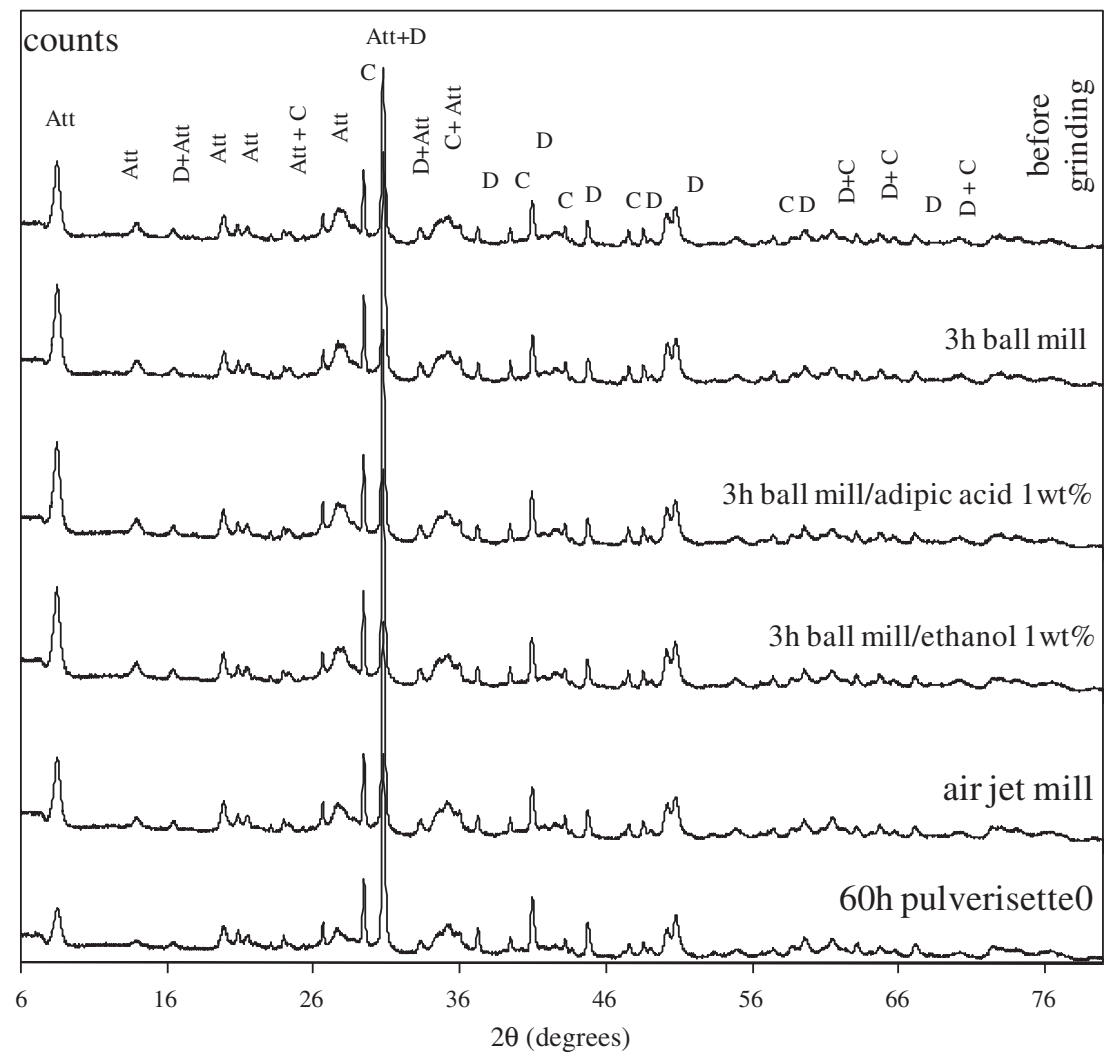

Fig. 8. X-ray diffraction patterns of attapulgite ground in ball mill, air jet mill and Pulverisette 0 (Att $=$ attapulgite, $C=$ calcite, $D=$ dolomite). 
Table 4

Values of specific surfaces areas $\left(\mathrm{a}_{\mathrm{BET}}\right)$, BET constants $\left(\mathrm{C}_{\mathrm{BET}}\right)$, microporous $\left(\mathrm{V}_{\text {micro }}\right)$ and mesoporous $\left(\mathrm{V}_{\text {meso }}\right)$ volumes, ground in the three devices in dry way.

\begin{tabular}{|c|c|c|c|c|c|}
\hline & & $\mathrm{a}_{\mathrm{BET}}\left(\mathrm{m}^{2} / \mathrm{g}\right)$ & $\mathrm{C}_{\mathrm{BET}}$ & $V_{\text {meso }}\left(\mathrm{cm}^{3} / \mathrm{g}\right)$ & $\mathrm{V}_{\text {micro }}\left(\mathrm{cm}^{3} / \mathrm{g}\right)$ \\
\hline Before grinding & & 125.1 & 436 & 0.302 & 0.018 \\
\hline \multirow[t]{3}{*}{ Ball mill } & $3 \mathrm{~h}$ & 100.3 & 182 & 0.340 & 0.009 \\
\hline & $3 \mathrm{~h}$ (1 wt.\% ethanol) & 78.8 & 150 & nd & nd \\
\hline & $3 \mathrm{~h}$ ( 1 wt.\% adipic acid $)$ & 75.8 & 170 & nd & nd \\
\hline Air jet mill & (1) & 93.3 & 248 & 0.331 & 0.010 \\
\hline \multirow[t]{2}{*}{ Pulverisette 0} & $3 \mathrm{~h}$ & 94.8 & 270 & nd & nd \\
\hline & $60 \mathrm{~h}$ & 66.3 & 221 & 0.254 & 0.013 \\
\hline
\end{tabular}

(nd) not determined.

In conclusion, the morphology of fibres after grinding is closely related to the nature of the solid and the grinding mechanism, which is governed by the differences in mechanical stress and the grinding conditions. In the case of the attapulgite, and except for the sample ground during $60 \mathrm{~h}$ in Pulverisette 0 , the different mechanical stresses induced fragmentation of the fibres without altering the original fibrous morphology. After a long-time $(60 \mathrm{~h})$ milling in Pulverisette 0 , the stress forces were strong enough to destroy the fibrous structure, leading to round shaped particle agglomerates. This observation is in agreement with the particle size distribution analysis.

Grinding can also affect the microstructure of powders. X-ray diffraction analysis was performed to evaluate the possible impact of grinding on the attapulgite microstructure.

\subsection{Analysis of microstructure and crystallite properties by X-ray diffrac- tion $(X R D)$}

Mineralogical analysis, carried out by XRD on dry-ground samples is presented in Fig. 8.

The diffraction patterns of the raw material did not change after grinding in the ball mill, in the presence or absence of additives. The microstructure of the attapulgite was, therefore, preserved in the course of grinding in the ball mill as well as the air jet mill.

The XRD analysis of the sample milled in Pulverisette 0 during $60 \mathrm{~h}$ showed no significant change in the pattern compared to that of the raw attapulgite. The crystalline structure was kept in spite of the high decrease in particle size and the breakage of the fibres.

Other important surface parameters are the specific surface area and the pore volumes, which can be affected significantly by the grinding processes.

\subsection{BET surface analysis}

Table 4 shows the specific surface area values $\left(\mathrm{a}_{\mathrm{BET}}\right)$, BET constants $\left(\mathrm{C}_{\mathrm{BET}}\right)$ and pore volumes, determined using the nitrogen adsorption isotherms of the attapulgite samples ground in the three grinding devices.

The dry grinding of attapulgite caused a significant decrease in specific surface area.

In the case of the non-porous solid, the reduction of the particle size led to an increase in external surface, which consequently induced an increase in specific surface area.

In the case of porous solids, the surface area includes both the external surface of the particles and their internal porous surface. The reduction of particle size in the case of a porous solid does not systematically induces an increase in surface area $[5,43]$. In the case of attapulgite, the reduction of particle size was accompanied by a decrease in the values of specific surface area, especially after $60 \mathrm{~h}$ of grinding in Pulverisette 0 . The observed decrease may be explained by changes in the internal structure of attapulgite. The specific surface area of attapulgite is mainly generated by internal pores, especially the micropores (Table 4), and the microporous volume decreased compared to the value observed in the case of the raw material.

Studies were performed on another fibrous clay, the sepiolite, which has a similar crystalline structure. The authors suggested the possibility of creating amorphous particles during grinding. These ones would be adsorbed onto the micropores and contributed to their closing. This interpretation was proposed by Vucelic [41] for the milling of a Serbian sepiolite in a ball mill. The value of the specific surface area increased from $243 \mathrm{~m}^{2} / \mathrm{g}$ to $253 \mathrm{~m}^{2} / \mathrm{g}$ after $24 \mathrm{~h}$, and to $236 \mathrm{~m}^{2} / \mathrm{g}$ after $120 \mathrm{~h}$ of milling. The author attributed the increase in surface value during the first $24 \mathrm{~h}$ of grinding to the separation of the sepiolite fibres, while the decrease after $120 \mathrm{~h}$ was explained by the destruction of channels and to amorphization. In another study on a Spanish sepiolite [42], grinding in a ball mill caused an increase in the specific surface area during the first $15 \mathrm{~min}$, without altering the crystal structure. At the same time, the particle surface was affected when milling for $1-8 \mathrm{~h}$. Mainly the tetrahedral sheets were destructed according to the IR analysis. Grinding caused, therefore, a decrease in the specific surface area because the formed amorphous particles, acting as a cementing agent, coated the unaffected ones, according to the authors. Milling for $14-24 \mathrm{~h}$ induced a complete amorphization of the solid.

In our work, in the case of attapulgite ground for $60 \mathrm{~h}$ in Pulverisette 0 , we can suppose that the carbonates may have plugged the micropores. To verify this hypothesis, a clay sample, devoided of carbonates by an acid treatment, was milled in Pulverisette 0 under the same conditions. The values of the specific surface area after grinding coupled with acid treatment were higher than those observed after a single grinding step without acid treatment. This phenomenon has already been observed [23] and can be attributed to the elimination of carbonates. Regarding the influence of the grinding time after the acid treatment, the specific surface area decreased with the milling time (Fig. 9) in spite of the absence of carbonates. This trend indicates that the decrease after $60 \mathrm{~h}$ grinding in Pulverisette 0 (without the acid treatment) was only due to the change in the internal structure of the attapulgite, and not to plugs in the pores formed by the carbonates. The destruction

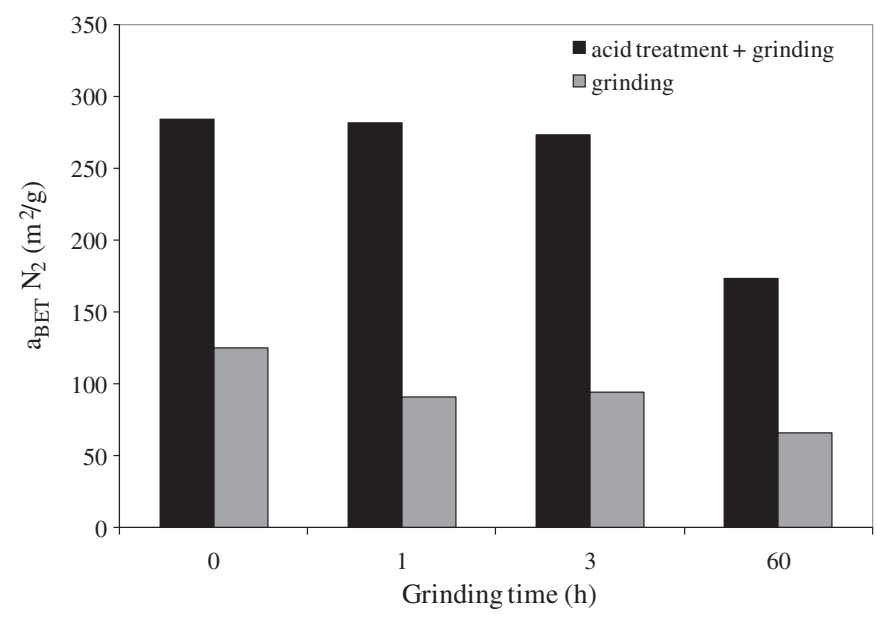

Fig. 9. Histogram of ground attapulgite at different times in Pulverisette 0, with and without acid treatment. 
Table 5

Values of $\gamma_{s}^{\mathrm{d}}, I_{M}\left(\chi_{t}\right)$ and $\mathrm{I}_{\mathrm{sp}}$ of attapulgite ground in dry way, measured at $130{ }^{\circ} \mathrm{C}$.

\begin{tabular}{|c|c|c|c|c|c|}
\hline & & \multirow{2}{*}{$\begin{array}{l}\gamma_{s}^{d}\left(\mathrm{~mJ} / \mathrm{m}^{2}\right) \\
\pm 4 \% \\
\mathrm{C} 6, \mathrm{C} 7, \mathrm{C} 8\end{array}$} & \multirow{2}{*}{$\begin{array}{l}I_{M}\left(\chi_{t}\right) \\
\pm 5 \% \\
\text { Cycl 8 }\end{array}$} & \multicolumn{2}{|c|}{$\begin{array}{l}\mathrm{I}_{\mathrm{sp}}(\mathrm{kJ} / \mathrm{mol}) \\
\pm 4 \%\end{array}$} \\
\hline & & & & $\mathrm{CH}_{2} \mathrm{Cl}_{2}$ & $\mathrm{CHCl}_{3}$ \\
\hline \multicolumn{2}{|l|}{ Before grinding } & 164 & 0.22 & 17 & 14 \\
\hline \multirow[t]{3}{*}{ Ball mill } & $3 \mathrm{~h}$ & 148 & 0.23 & 16 & 13 \\
\hline & 3 h (1 wt.\% ethanol) & 146 & 0.23 & 15 & 12 \\
\hline & $3 \mathrm{~h}$ ( 1 wt.\% adipic acid $)$ & 152 & 0.22 & 15 & 13 \\
\hline Air jet mill & - & 159 & 0.20 & 16 & 14 \\
\hline \multirow[t]{2}{*}{ Pulverisette 0} & $10 \mathrm{~h}$ & 142 & 0.27 & 17 & 14 \\
\hline & $60 \mathrm{~h}$ & 116 & 0.33 & 17 & 14 \\
\hline
\end{tabular}

of channels composing the attapulgite structure can explain the decrease in the specific surface area. The increase in density shown using a helium pycnometer, supports this interpretation. It increased from $2.49 \mathrm{~cm}^{3} / \mathrm{g}$ to $2.80 \mathrm{~cm}^{3} / \mathrm{g}$ after $60 \mathrm{~h}$ of grinding in Pulverisette 0 , due to the disappearance of the pores.

The application of additives (adipic acid and ethanol) caused a further decrease in the specific surface area in the case of ball mill grinding: from $100 \mathrm{~m}^{2} / \mathrm{g}$ (without additives) to values slightly lower than $80 \mathrm{~m}^{2} / \mathrm{g}$. The additives, however, did not prevent changes in the internal structure of the attapulgite in the course of grinding.

After reviewing the effects of grinding on textural and morphological properties, the modifications in surface properties were investigated using inverse gas chromatography.

\subsection{Determination of surface properties of the ground samples by IGC}

4.5.1. Inverse gas chromatography of ground samples at infinite dilution (IGC-ID)

Table 5 displays the values of the dispersive components of surface energy, $\gamma_{s}^{d}$, the morphological index, $I_{M}\left(\chi_{t}\right)$, and the specific components of surface energy, $I_{\mathrm{sp}}$, of raw and dry-ground attapulgite, measured at $130{ }^{\circ} \mathrm{C}$.

Whatever the grinding process, the dispersive component of the surface energy of ground samples decreased slightly, except after $60 \mathrm{~h}$ of grinding in Pulverisette 0 . In this last case, $\gamma_{s}^{d}$ changed from $164 \mathrm{~mJ} / \mathrm{m}^{2}$ to $116 \mathrm{~mJ} / \mathrm{m}^{2}$ during grinding. This change reflects the disappearance of structural defects under mechanical stresses, reducing the ability of alkane probes to adsorb on the solid surface. The hypothesis is confirmed by the increasing of the nanomorphology index $I_{M}\left(\chi_{t}\right)$, obtained by injecting the cyclooctane probe. This increase reflects the reduction of surface roughness during $60 \mathrm{~h}$ of milling in Pulverisette 0 .

Taking into account the error in measurement, the values of $I_{\mathrm{sp}}$ remained unchanged, which means that whatever the grinding process, the basic character of the surface area examined by acid probes, chloroform and dichloromethane is not affected by the mechanical stress.
In summary, the parameters obtained by IGC-ID confirmed the weak influence of the dry milling processes on the surface properties of attapulgite except for the $60 \mathrm{~h}$ milling in Pulverisette 0 . In this vibrating device, the structure is strongly affected by the high specific energy brought by multi-impacts on the powder, inducing subsequently significative surface modifications.

The BET analysis showed a decrease of the specific surface area despite grinding and a decrease of the particle size. The IGC-ID brought new information in connection with the interaction potential of the surface: the disappearance of apolar adsorption sites testified by the decrease of the dispersive component of the surface energy.

The IGC-ID parameters are clearly related to the adsorption sites having the highest energy of interaction [30]. The IGC-FC analysis was then used to provide information on the whole surface of the analysed samples.

\subsubsection{Inverse gas chromatography of ground samples at finite concentration (IGC-FC)}

4.5.2.1. Determination of specific surface area. The characteristic parameters obtained by nitrogen adsorption and IGC-FC by injecting n-octane and isopropanol probes, are collected in Table 6.

The specific surface areas measured with nitrogen at $77 \mathrm{~K}$ were close to those measured with the octane probe. On the contrary, application of isopropanol led to smaller values. This difference could be attributed to the structure of the probes (polarity and steric hindrances) and to the fact that the polar isopropanol probe adsorbs only on the most polar part of the surface. It can also be explained by the more irreversible character of the isopropanol adsorption compared to that of n-octane, as confirmed by their respective irreversibility indices $\left(I_{\text {irr }}\right)$. As shown in Table 6 , the $I_{\text {irr }}$ values obtained with isopropanol were higher than those with octane, giving evidence that a higher part of isopropanol adsorbed irreversibly on the solid surface at the temperature of analysis. This irreversible adsorption contributed to the decrease in the measured specific surface areas computed from the reversible part of the adsorption phenomenon. The irreversibility indices, $I_{\mathrm{irr}}$, provide additional information: the high values obtained with isopropanol prove that milling led to high energy sites on the solid surface that could form hydrogen bonds with the alcohol probe. According to the highest values of $I_{\text {irr }}$ after milling for 10 or $60 \mathrm{~h}$ in Pulverisette 0 , this way of grinding seems to have generated the most high energy sites, probably silanol groups.

The influence of grinding on the specific surface area, calculated by nitrogen adsorption and IGC-FC, was also examined. It is to note that whatever the grinding mode, the changes in the specific surface area obtained with both organic probes were in agreement with those obtained with nitrogen. A slight decrease was observed, except for the case of the sample ground in Pulverisette 0 for $60 \mathrm{~h}$. As previously said, this

Table 6

Values of the specific surface areas $\left(\mathrm{a}_{\mathrm{BET}}\right)$, BET constants $\left(\mathrm{C}_{\mathrm{BET}}\right)$ and irreversibility indexes $\left(\mathrm{I}_{\mathrm{irr}}\right)$ of attapulgite before and after grinding, obtained by nitrogen adsorption and IGC-FC (with octane C8 and isopropanol IP).

\begin{tabular}{|c|c|c|c|c|c|c|c|c|c|}
\hline & & \multirow{2}{*}{\multicolumn{2}{|c|}{ Adsorption $\mathrm{N}_{2}$}} & \multicolumn{6}{|l|}{ IGC-FC } \\
\hline & & & & \multicolumn{3}{|l|}{$\mathrm{C} 8\left(53^{\circ} \mathrm{C}\right)$} & \multicolumn{3}{|l|}{$\operatorname{IP}\left(43^{\circ} \mathrm{C}\right)$} \\
\hline & & $\mathrm{a}_{\mathrm{BET}}\left(\mathrm{m}^{2} / \mathrm{g}\right)$ & $\mathrm{C}_{\mathrm{BET}}$ & $\begin{array}{l}\mathrm{a}_{\mathrm{BET}}\left(\mathrm{m}^{2} / \mathrm{g}\right) \\
\pm 2.8\end{array}$ & $\mathrm{C}_{\mathrm{BET}}$ & $\begin{array}{l}\mathrm{I}_{\mathrm{irr}}(\%) \\
\pm 0.2\end{array}$ & $\begin{array}{l}\mathrm{a}_{\mathrm{BET}}\left(\mathrm{m}^{2} / \mathrm{g}\right) \\
\pm 4\end{array}$ & $\mathrm{C}_{\mathrm{BET}}$ & $\begin{array}{l}\mathrm{I}_{\mathrm{irr}}(\%) \\
\pm 0.6\end{array}$ \\
\hline Before grinding & & 125.1 & 437 & 114.5 & 9 & 0.6 & 71 & 22 & 8.3 \\
\hline \multirow[t]{3}{*}{ Ball mill } & $3 \mathrm{~h}$ & 100.3 & 182 & 92.6 & 9 & 0.7 & 68 & 17 & 12.3 \\
\hline & $3 \mathrm{~h}$ (1 wt.\% ethanol) & 75.8 & 170 & 90.3 & 8 & 0.4 & 73 & 17 & 17.4 \\
\hline & $3 \mathrm{~h}$ ( 1 wt.\% adipic acid) & 78.8 & 150 & 80.8 & 9 & 1.7 & 75 & 19 & 15.0 \\
\hline Air jet mill & - & 93.3 & 249 & 75.6 & 9 & 1.2 & 60 & 19 & 15.9 \\
\hline \multirow[t]{3}{*}{ Pulverisette 0} & $3 \mathrm{~h}$ & 94.8 & 271 & 86.7 & 9 & 1.5 & 73 & 20 & 16.2 \\
\hline & $10 \mathrm{~h}$ & 100.2 & 365 & 86.4 & 11 & 1.7 & 76 & 23 & 20.2 \\
\hline & $60 \mathrm{~h}$ & 66.3 & 221 & 62.6 & 8 & 1.2 & 47 & 25 & 23.4 \\
\hline
\end{tabular}


(a)

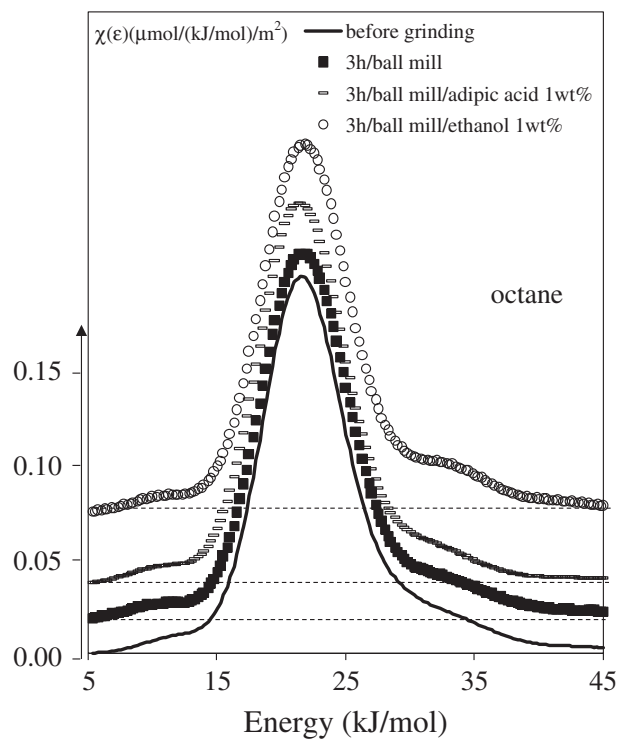

(b)

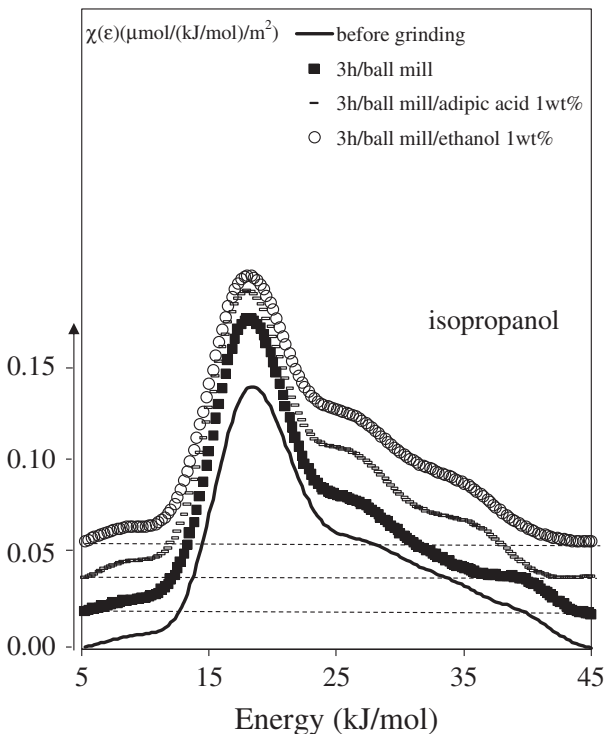

Fig. 10. Distribution functions of the adsorption energies with n-octane (a) and isopropanol (b) probes measured on attapulgite samples ground $3 \mathrm{~h}$ in ball mill, without additives and in the presence of additives (adipic acid and ethanol).

variation can be explained by the alteration of the internal structure of particles (physical alteration, such as the disappearance of porosity). The channel structure resulting from the inversion of the tetrahedral silica [35] could explain the trend under grinding of the attapulgite.

The BET constants measured using nitrogen adsorption (Table 4) were much higher than those obtained by IGC-FC with octane and isopropanol, reflecting a greater affinity of nitrogen to the surface of ground attapulgite. A likely explanation is the difference in the analysis temperatures ( $77 \mathrm{~K}$ for nitrogen and 316 or $326 \mathrm{~K}$ for the octane or isopropanol). The higher the analysis temperature was, the weaker the surface-probe interactions and the lower the BET constant.

In conclusion, independently from the injected probe and the grinding process, surface properties of ground attapulgite remained approximately the same for at least up to $3 \mathrm{~h}$ except after grinding for $60 \mathrm{~h}$ in Pulverisette 0 . In this last case, the high energy brought by multi-impacts between the ball and particles, induced subsequently significative surface modifications.

4.5.2.2. Characterization of surface heterogeneity. Fig. 10 shows the influence of grinding in a ball mill on the distribution functions of the adsorption energies (DFAE) measured on attapulgite, with the two probes, n-octane and isopropanol.

Both probes indicated that grinding in the ball mill did not change the DFAE in the presence and absence of additives. These results demonstrate that the grinding did not cause a significant change in surface (a)

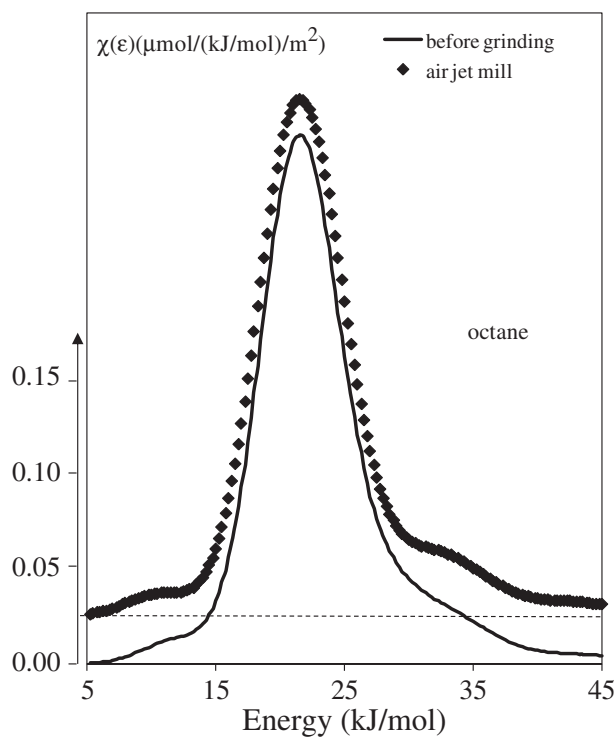

(b)

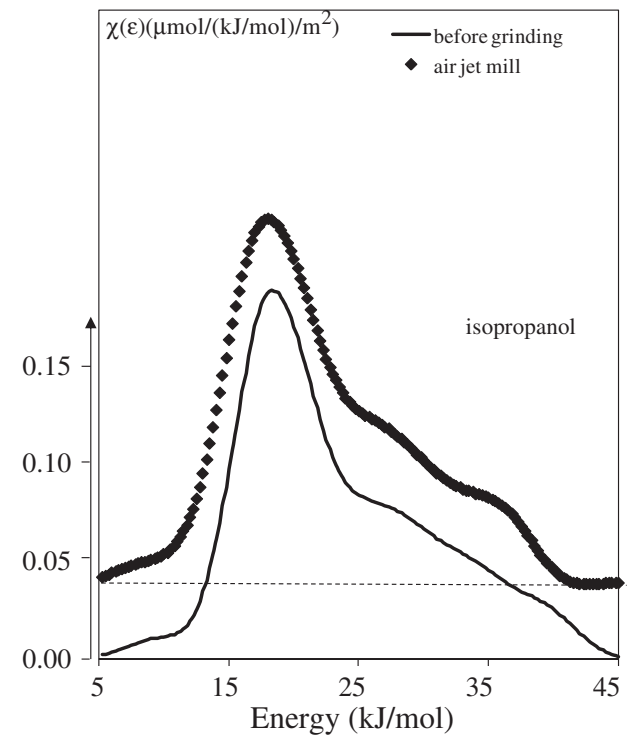

Fig. 11. Distribution functions of the adsorption energies with n-octane (a) and isopropanol (b) of attapulgite before and after grinding in air jet mill. 
(a)

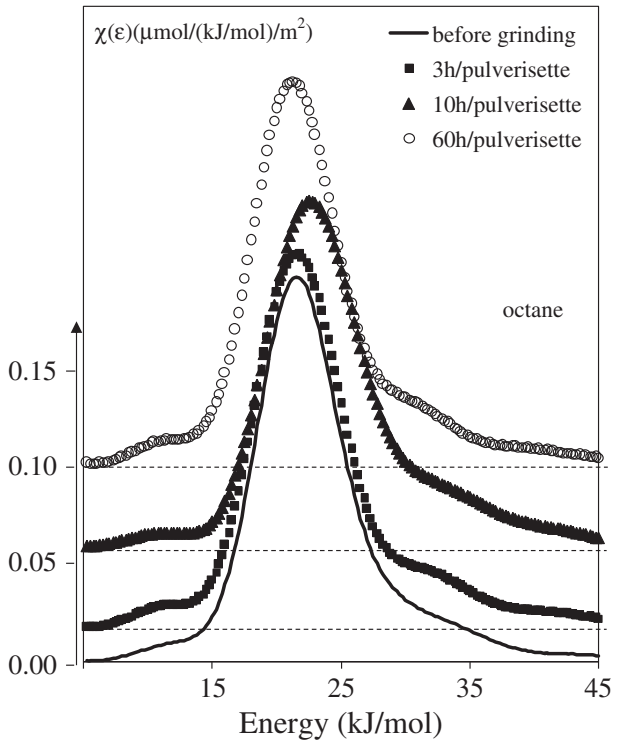

(b)

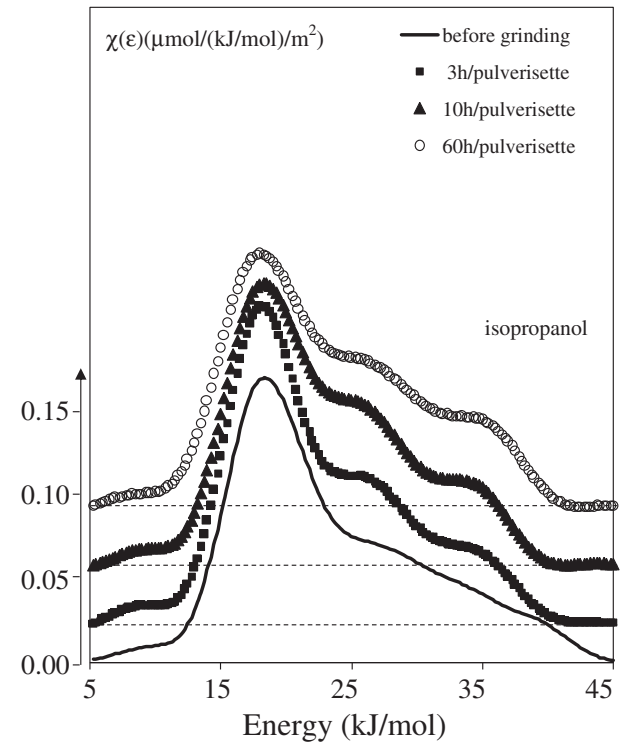

Fig. 12. Distribution functions of the adsorption energies with n-octane (a) and isopropanol (b) of attapulgite before and after grinding in Pulverisette 0 , at different times.

heterogeneity of attapulgite fibres, at least for a ball milling time shorter than $3 \mathrm{~h}$.

The distribution functions obtained with octane and isopropanol were also slightly affected by grinding in air jet mill (Fig. 11).

Grinding in Pulverisette 0 altered the shape of the distribution function obtained with isopropanol more than the one obtained with octane (Fig. 12). After $3 \mathrm{~h}$ of grinding, the shoulders at high energies were pronounced and became more intense proportionally with the duration of milling, indicating the appearance of polar sites that could strongly interact with the isopropanol probe. This result is in agreement with the increase in $\mathrm{I}_{\mathrm{irr}}$. The detachment of some fibres in the matrix may be responsible for the formation of these new sites, such as hydroxyl functions.

The heterogeneity index values ( $I_{\text {hete }}$ ) were much higher with isopropanol (Table 7) than with octane. These differences highlight the higher ability of isopropanol to detect surface heterogeneity by binding to polar sites.

Heterogeneity index values calculated with the two probes are not significantly affected by the different modes of grinding

\section{Conclusion}

The dry grinding in ball mill, air jet mill and Pulverisette 0 reduced the particle size of attapulgite significantly. Despite the high decrease in the particle size in the case of shorter grinding durations, the fibrous morphology was preserved independently from the grinding process.

Table 7

Heterogeneity ( $\mathrm{I}_{\text {hete }}$ ) index values (in percent), measured by IGC-FC with octane and isopropanol probes, on attapulgite samples after dry grinding.

\begin{tabular}{|c|c|c|c|}
\hline & & $\mathrm{C} 8\left(53^{\circ} \mathrm{C}\right)$ & $\operatorname{IP}\left(43^{\circ} \mathrm{C}\right)$ \\
\hline & & $\mathrm{I}_{\text {hete }}(\%) \pm 1.2$ & $\mathrm{I}_{\text {hete }}(\%) \pm 4.9$ \\
\hline \multicolumn{2}{|l|}{ Before grinding } & 13.6 & 41.2 \\
\hline \multirow{3}{*}{ Ball mill } & $3 \mathrm{~h}$ & 11.7 & 34.5 \\
\hline & 3 h (1 wt.\% ethanol) & 14.7 & 39.5 \\
\hline & $3 \mathrm{~h}$ (1 wt.\% adipic acid) & 11.2 & 36.8 \\
\hline Air jet mill & - & 13.8 & 41.9 \\
\hline \multirow[t]{3}{*}{ Pulverisette 0} & $3 \mathrm{~h}$ & 16.3 & 36.2 \\
\hline & $10 \mathrm{~h}$ & 19.4 & 40.8 \\
\hline & $60 \mathrm{~h}$ & 15.3 & 46.5 \\
\hline
\end{tabular}

On the contrary, a longer duration in Pulverisette 0 destroyed the fibres completely, inducing a significant decrease in the specific surface area, from 125.1 to $66.3 \mathrm{~m}^{2} / \mathrm{g}$.

The grinding stress slightly affected the parameters obtained by IGC, except once again for Pulverisette 0. In IGC-ID, the most sensitive parameter was the dispersive component of the surface energy $\left(\gamma_{s}^{d}\right)$ established with the injection of linear alkanes. After $60 \mathrm{~h}$ milling in Pulverisette 0 , the $\gamma_{s}^{d}$ decreased from 164 to $116 \mathrm{~mJ} / \mathrm{m}^{2}$ in contrast with of 148 and 159 obtained with ball mill and air jet mill, respectively. The simultaneous decreases in the specific surface area and of the $\gamma_{s}^{d}$ can be interpreted by a destruction of channels forming the attapulgite structure. In this vibrating device, the specific energy brought by multi-impacts on the powder was high enough to strongly affect morphology and surface properties of attapulgite.

In CGI-FC, descriptive variables in connection with the interaction at high energy sites, namely the irreversibility index and distribution function obtained with isopropanol seemed to prove that this mode of grinding created new surfaces with silanol groups. For example, the irreversibility index, $I_{\text {irr }}$, increased from 8.3 to 23.4 after $60 \mathrm{~h}$ milling. In the two other grinding modes that were softer than Pulverisette 0 , less new surfaces were created, $I_{\text {irr }}$ only increased to 12.3 and 15.9 when grinding in ball mill and in air jet mill, respectively. The fibrous morphology of the attapulgite, also exhibiting a high specific surface area and elasticity, will facilitate the dissipation of grinding energy.

\section{References}

[1] J. Hrachová, P. Komadel, V.Š. Fajnor, The effect of mechanical treatment on the structure of montmorillonite, Mater. Lett. 61 (2007) 3361-3365.

[2] N. Vdovic, I. Jurina, S.D. Skapin, I. Sondi, The surface properties of clay minerals modified by intensive dry milling-revisited, Appl. Clay Sci. 48 (2010) 575-580.

[3] M. Valášková, K. Barabaszová, M. Hundáková, M. Ritz, E. Plevová, Effects of brief milling and acid treatment on two ordered and disordered kaolinite structures, Appl. Clay Sci. 54 (2011) 70-76.

[4] E. Mendelovici, Selective mechanochemical reactions on dry grinding structurally different silicates, J. Mater. Sci. Lett. 20 (2001) 81-83.

[5] G. Suraj, C.S.P. Iyer, S. Rugmini, M. Lalithambika, The effect of micronization on kaolinite and their sorption behaviour, Appl. Clay Sci. 12 (1997) 111-130.

[6] M. Zbik, R.S.C. Smart, Influence of dry grinding on talc and kaolinite morphology: inhibition of nano-bubble formation and improved dispersion, Miner. Eng. 18 (2005) 969-976.

[7] M.I. Mahadi, S. Palaniandy, Mechanochemical effect of dolomitic talc during fine grinding process in mortar grinder, Int. J. Miner. Process. 94 (2010) 172-179.

[8] S. Palaniandy, A. Samayamutthirian, K.A.M. Azizli, Mechanochemical effects on talc during fine grinding process in a jet mill, Int. J. Miner. Process. 92 (2009) 22-23. 
[9] K. Terada, E. Yonemochi, Physicochemical properties and surface free energy of ground talc, Solid State Ionics 172 (2004) 459-462.

[10] M. Yekeler, U. Ulusoy, C. Hicyilmaz, Effect of particle shape and roughness of talc mineral ground by different mills on the wettability and floatability, Powder Technol. 140 (2004) 68-78.

[11] H. Suquet, Effects of dry grinding and leaching on the crystal-structure of chrysotile, Clay Clay Miner. 37 (1989) 439-445.

[12] E. Papirer, P. Roland, Grinding of chrysotile in hydrocarbons, alcohol, and water, Clay Clay Miner. 29 (1981) 161-170.

[13] T. Hongo, S. Yoshino, A. Yamazaki, A. Yamasaki, S. Satokawa, Mechanochemical treatment of vermiculite in vibration milling and its effect on lead (II) adsorption ability, Appl. Clay Sci. 70 (2012) 74-78.

[14] C. Maqueda, J.L. Perez-Rodriguez, J. Subrt, N. Murafa, Study of ground and unground leached vermiculite, Appl. Clay Sci. 44 (2009) 178-184.

[15] Y. Liu, W. Wang, A. Wang, Effect of dry grinding on the microstructure of palygorskite and adsorption efficiency for methylene blue, Powder Technol. 225 (2012) 124-129.

[16] Y. Liu, H. Chen, J. Zhang, A. Wang, Effect of number of grindings of attapulgite on enhanced swelling properties of the superabsorbent nanocomposites, J. Compos. Mater 47 (2013) 969-978.

[17] J.L. Perez-Rodriguez, C. Maqueda, N. Murafa, J. Subrt, V. Balek, P. Pulisova, A. Lancok, Study of ground and unground leached vermiculite II. Thermal behaviour of ground acid-treated vermiculite, Appl. Clay Sci. 51 (2011) 274-282.

[18] H. Balard, D. Maafa, A. Santini, J.B. Donnet, Study by inverse gas chromatography of the surface properties of milled graphites, J. Chromatogr. A 1198-1199 (2008) 173-180.

[19] H. Balard, O. Aouadj, E. Papirer, Monitoring, by inverse gas chromatography, of the variation of the surface energetic heterogeneity of ground muscovite samples, Langmuir 13 (1997) 1251-1255.

[20] E. Papirer, J.M. Perrin, B. Siffert, G. Philipponneau, J.M. Lamerant, The influence of grinding on the surface properties of $\alpha$-aluminas, J. Colloid Interface Sci. 156 (1993) 104-108

[21] H.H. Murray, Applied clay mineralogy today and tomorrow, Clay Clay Miner. 34 (1999) 39-49.

[22] H.H. Murray, traditional and new applications for kaolin, smectite, and palygorskite: a general overview, Appl. Clay Sci. 17 (2000) 207-221.

[23] L. Boudriche, R. Calvet, B. Hamdi, H. Balard, Effect of acid treatment on surface properties evolution of attapulgite clay: an application of inverse gas chromatography, Colloids Surf., A 392 (2011) 45-54.

[24] C. Tisserand, Etude par chromatographie gazeuse inverse des propriétés de surface de deux formes cristallographiques d'alumines: influence de différents paramètres tels l'humidité ou le dopage en magnésie, (PhD thesis) University of Haute Alsace, 2009.

[25] B. Hamdi, Z. Kessaïsia, J.B. Donnet, T.K. Wang, IGC characterization of surface energy and morphology of two natural fillers: kieselguhr and bentonite, Ann. Chim. Sci. Mater. 25 (2000) 481-494.
[26] A.B. Nastasovic, A.E. Onjia, Determination of glass temperature of polymers by inverse gas chromatography, J. Chromatogr. A 1195 (2008) 1-15.

[27] V. Swaminathan, J. Cobb, I. Saracovan, Measurement of the surface energy of lubricated pharmaceutical powders by inverse gas chromatography, Int. J. Pharm. 312 (2006) 158-165.

[28] E. Cantergiani, D. Benczédi, Use of inverse gas chromatography to characterize cotton fabrics and their interactions with fragrance molecules at controlled relative humidity, J. Chromatogr. A 969 (2002) 103-110.

[29] G.M. Dorris, D.G. Gray, Adsorption of n-alkanes at zero surface coverage on cellulose paper and wood fibers, J. Colloid Interface Sci. 77 (1980) 353-362.

[30] E. Brendlé, E. Papirer, A new topological index for molecular probes used in inverse gas chromatography for the surface nanorugosity evaluation. 1) method of evaluation, J. Colloid Interface Sci. 194 (1997) 207-216.

[31] H. Balard, E. Brendlé, E. Papirer, Determination of the acid-base properties of solid surfaces using inverse gas chromatography: advantages and limitations, in: K. Mittal (Ed.), Acid-Base Interactions, Relevance to Adhesion Science and TechnologyVSP, Utrecht, The Netherlands, 2000, pp. 299-316.

[32] M.P. Comard, R. Calvet, J. Dodds, H. Balard, Coupling of inverse gas chromatography at infinite dilution (IGC-ID) with a controlled modification of a solid surface, J. Chromatogr. 969 (2002) 93-96.

[33] J.R. Conder, C.L. Young, Physicochemical Measurements by Gas Chromatography, Wiley Interscience, New York, 1979. 385-390.

[34] W. Rudzinski, J. Jagiello, Y. Grillet, Physical adsorption of gases on heterogeneous solid surface: evaluation of the adsorption energy distribution from adsorption isotherms and heats of adsorption, J. Colloid Interface Sci. 87 (1982) 478-491.

[35] W.F. Bradley, The structural scheme of attapulgite, Am. Mineral. 25 (1940) 405-410

[36] A. Chahi, S. Petit, A. Decarreau, Infrared evidence of dioctahedral-trioctahedral site occupancy in palygorskite, Clay Clay Miner. 50 (2002) 306.

[37] M. Suarez, E. Garcia-Romero, FTIR spectroscopic study of palygorskite: influence of the composition of the octahedral sheet, Appl. Clay Sci. 31 (2006) 154-163.

[38] E. Garcia-Romero, M. Suarez Barrios, M.A. Bustillo Revuelta, Characteristics of a Mg-palygorskite in Miocene rocks, Madrid Basin (Spain), Clay Clay Miner. 52 (2004) 484-494.

[39] L. Boudriche, B. Hamdi, Z. Kessaïssia, R. Calvet, A. Chamayou, J.A. Dodds, H. Balard, An assessment of the surface properties of milled attapulgite using inverse gas chromatography, Clay Clay Miner. 58 (2010) 143-153.

[40] P.A. Rehbinder, L.A. Schreiner, K.F. Zhigach, Hardness Reducers in Drilling, Trans Council of Scientific and Industrial Research, Melbourne, 1948. 163-172.

[41] D. Vucelic, D. Simic, O. Kovacevic, M. Dojcinova, M. Mitrovic, The effects of grinding on the physicochemical characteristics of white sepiolite from Golesh, J. Serb. Chem. Soc. 67 (2002) 197-211.

[42] J. Cornejo, M.C. Hermosin, Structural alteration of sepiolite by dry grinding, Clay Miner. 23 (1988) 391-398.

[43] F. Dellisanti, G. Valdrè, M. Mondonico, Changes of the main physical and technological properties of talc due to mechanical strain, Appl. Clay Sci. 42 (2009) 398-404. 